\title{
Using grading to motivate staff in agricultural enterprises
}

\author{
Sergey Yekimov ${ }^{1, *}$, Nataliia Otroshchenko ${ }^{2}$, Yuliya Voytsekhovska $^{3}$, Svitlana Nakhod $^{4}$, and \\ Tetiana Gavrilko ${ }^{5}$ \\ ${ }^{1}$ Publishing House "Education and Science" s.r.o., Olstynska, 607/1, 18100, Praha, Czech Republic \\ ${ }^{2}$ Luhansk Taras Shevchenko national University, Starobilsk, Ukraine \\ ${ }^{3}$ Lviv Polytechnic National University, Lviv ,Ukraine \\ ${ }^{4}$ Alfred Nobel University, Dnipro, Ukraine \\ ${ }^{5}$ National Aviation University, Kyiv, Ukraine
}

\begin{abstract}
In the context of the COVID-19 pandemic and the associated difficulties in the functioning of agricultural enterprises, in our opinion, new approaches are required to improve the efficiency of agricultural enterprises. The economic efficiency of an agricultural enterprise depends to a large extent on the efficiency of its personnel. In our opinion, human resources are one of the most important resources in the agricultural business.In this paper, we considered the use of grading to motivate employees of an agricultural enterprise . In our opinion, this will assist in the formation of a clear and transparent system of payment for work activities for the company's employees and, in addition, will optimize the size of the company's employee compensation fund.The system of management of labor resources of the agricultural enterprise should take into account the personality of the employee, knowledge of his features of motivation, and also be combined with the goals and objectives that the enterprise has.
\end{abstract}

\section{Introduction}

Improving the competitiveness of agricultural enterprises is currently of great importance. Therefore, the identification and search for new opportunities, in our opinion, will allow us to achieve success in the medium and long-term development of the enterprise, will allow us to produce products of higher quality and increase the volume of sales of products.

The activity of an agricultural enterprise involves the performance of low-skilled work on the collection of fruits and vegetables, as well as the management of agricultural machinery, which requires the possession of certain competencies by employees. Agricultural production in comparison with mechanical engineering is less automated and robotic, so its production indicators depend on the human factor. Therefore, in our opinion, for the management of agricultural enterprises, it is of paramount importance to find the

\footnotetext{
* Corresponding author: 3701313@mail.ru
} 
most effective methods of managing the personnel of the enterprise in order to achieve the maximum and most complete disclosure of their labor potential.

According to Harris, Perrethia \& Howitt, Genevieve \& Jones, Nancy. (1996) not all enterprises of the agricultural sector working on issues related to strategic management, this is due to the specificity of agricultural production, insufficient financial resources and lack of appropriate specialists.

According to Strus, R.V. \& Koval, O.G. \& Myshko, O.V. (2018) personnel management of enterprises is the implementation of complex organizational, social and economic measures aimed at promoting the formation of the necessary conditions for the effective use of the labor resources that the enterprise has.

In the opinion of Abegunasekara, Nadeesha. (2020) the company's human resource management system should represent a set of goals, tasks, as well as the most priority areas of the company's functioning, forms and methods of work. To achieve these goals, an appropriate management mechanism is required to ensure production efficiency. production of high-quality products and growth of labor productivity

According to Thompson, Neil. (2013), Oldcorn, Roger. (1989) human resources management can be carried out through the use of administrative resources. psychological, economic, and social methods.

Among the administrative methods are the authors Henderson, Amanda \& Schoonbeek, Sue \& Auditore, Anthony. (2013) Thiedke, C. (2004), Epaneshnikov, A. \& Lipatova, S.. (2020) select:

- Application of orders, job descriptions, rationing of labor activity.

- Maintaining a high level of labor discipline.

- The use of disciplinary punishments and penalties.

Among the most effective social and psychological methods, the authors of Lawrence, Kathy. (1984), Britnell, Mark. (2013) distinguish: retraining and advanced training of employees, providing additional days to the annual leave, time off, promoting the formation of a working atmosphere in the workplace, meeting cultural and spiritual needs, as well as the use of various mechanisms to ensure social protection for employees of the enterprise.

In progress Henney, Alan. (1996), Agomo, Chijioke. (2008) it is recommended to use teamwork as an additional management method.

According to Marr, Heather. (1992), Bartz, Dr. (2020) material incentives for individual employees and the entire workforce can be used as economic incentive methods. In our opinion, economic methods of stimulating employees of an agricultural enterprise play an important role in the management of its labor resources. The related aspects deserve further consideration. 


\section{Methods}

When conducting this research, we used an analytical method, which made it possible to study the problems discussed in the article in their development and unity. Taking into account the purpose and purpose of this research work, we used the functionalstructural method of scientific cognition. Taking into account the objectives and goals of this publication, we used the structural and functional method of scientific cognition. As a result, we were able to investigate some of the problems associated with the use of grading to motivate staff in agricultural enterprises.

\section{Results}

In the context of the COVID-19 pandemic and the associated difficulties in the functioning of agricultural enterprises, in our opinion, new criteria are required that would reflect the efficiency of agricultural enterprises. The economic efficiency of an agricultural enterprise largely depends on the efficiency of its employees. In our opinion, human resources are one of the most important resources in the agricultural business.

However, highly qualified personnel, as a rule, is a vulnerable and unstable labor resource available to an agricultural enterprise. We believe that highly qualified employees, and not seasonal workers, are the main labor resource of the enterprise. They are the ones who manage expensive and high-performance agricultural machinery.

In the conditions of tough market competition, success is achieved only by those agricultural enterprises that can offer their products at a favorable price for consumers, and this is difficult to do without highly qualified specialists.

According to $* * * * * * * * *$ motivation occupies an important place among the tools of personnel management. It allows you to increase the level of labor productivity in the enterprise, reduce staff turnover and achieve continuous improvement of the level of qualification of employees.

As a factor that motivates the work of employees according to $* * * * * * * *$ opinion, in addition to material incentives, the openness of the company's management to its staff, the presence of career growth, an objective assessment of the results of work, bonuses for many years of successful work, teamwork at the enterprise can act as motivating factors.

We adhere to the point of view that, for any employer, the optimal employee should be proactive, disciplined, have high spiritual values, and constantly strive to improve their professional level. However, it is very difficult to find such workers for an agricultural enterprise in practice. In this regard, we propose to use grading for the personnel management of an agricultural enterprise. It allows you to compare the value of the position for an agricultural enterprise, the value and demand for it in the labor market. And based on this, create a system of personnel motivation, taking into account that the grade is a group of positions of equal importance for the enterprise.

This, in our opinion, will allow us not only to better assess the usefulness of each employee for the company and the work they do, but also their professional qualifications and work experience. We believe this will allow us to retain the most qualified specialists at the agricultural enterprise.

We adhere to the point of view that grading should contain six stages.

Stage 1. Conducting workplace certification. To do this, you should determine and analyze the responsibilities that the employee performs, the amount of work performed, as well as with which employees he interacts during working hours. This makes it possible to find out what competencies an employee should have and the level of his responsibility for the company's activities. 
Stage 2. Finding out the type of employee's workload during the performance of their work duties. This allows you to determine what kind of mental or physical stress an employee is experiencing, and their length during working hours.

Step 3. The implementation of the ranking factors. Each factor (the need for competencies, the degree of mental and physical activity, the complexity of the work) is ranked using a 100-point system from 0 to 100 points

Stage 4. Summing up the scores for each factor under study. The end result is an integral indicator that determines the certification of the workplace.

Stage 5. The ranking of the integrated indicators of workplace certification obtained during the fourth stage is performed.

Step 6. The upper and lower limits of the salary amount for each certified workplace are determined.

We believe that using grading, it is possible to create a system of payment of wages that is clear and transparent for the employees of an agricultural enterprise and thus optimize the costs of paying employees of the enterprise.

We believe that control over the violation of the performance of their labor duties by employees of an agricultural enterprise should be based on team and personal responsibility, constant control based on an objective approach. We believe that these principles should be taken into account in the process of conducting inspections, managing production processes, encouraging employees, imposing penalties, and entering into employment contracts with employees.

We adhere to the point of view that motivation is the main driving force during work. The main forms of motivation of employees of agricultural enterprises are (Figure 1).

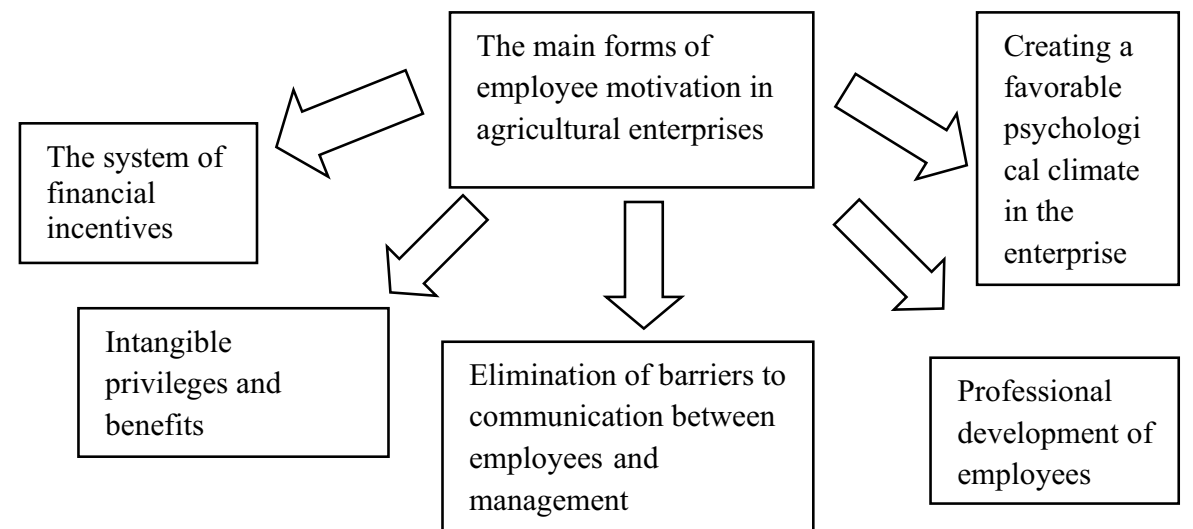

Fig. 1. The main forms of employee motivation in agricultural enterprises.

We believe that in order to ensure effective motivation for work in the company, it is necessary that the motivation system is clear to all employees. Employees of the company should understand that for showing initiative and good work, they can receive encouragement from the company's management in the form of a bonus, an additional day of vacation, time off or career growth.

\section{Discussion}

The use of strategic management of the company's labor resources in the agricultural business plays an important role for their optimal use. The management of the enterprise must know the methods of motivating the work of employees. Motivational incentives can 
be not only material, but also moral. In our opinion, the main principles of personnel management of an agricultural enterprise are (Figure 2):

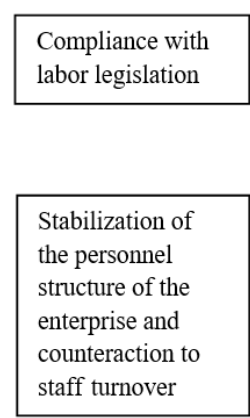

Respect for the opinions of each employee

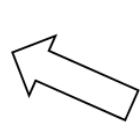

The main principles

of personnel

management of an

agricultural enterprise
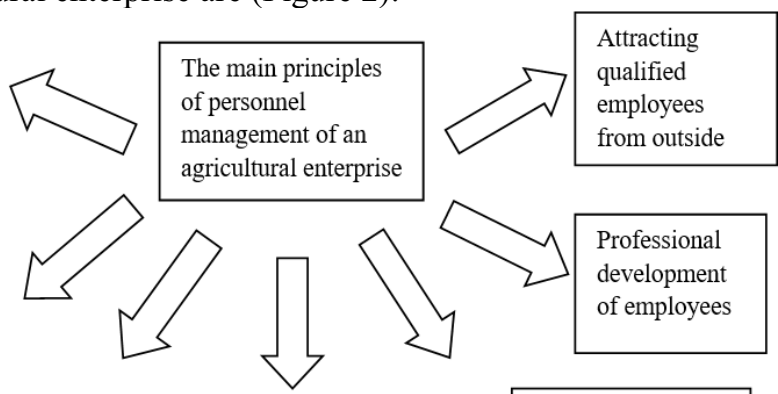

Maximum care for the needs of each employee, providing the necessary conditions for improving their skills
Professional development of employees

Determining the need for employees for the current time, as well as for the future

Fig. 2. The main principles of personnel management of an agricultural enterprise.

\section{Conclusion}

The authors believe that the labor management system of an agricultural enterprise should take into account the personality of the employee, knowledge of his motivation, and also be combined with the goals and objectives that the enterprise has.

In our opinion, work with the staff of an agricultural enterprise should be carried out in the following areas (Figure 3)
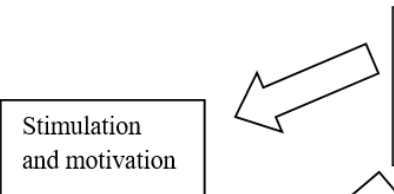

\section{Areas of work} with the personnel of the agricultural enterprise
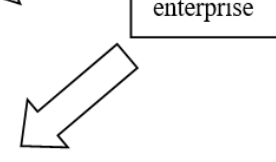

Administration

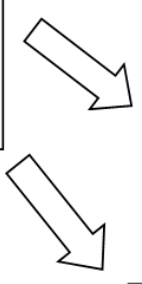

Prevention of

abuse of

personnel in the

workplace

Professional development and training of employees

Fig. 3. Areas of work with the personnel of the agricultural enterprise.

The use of socially-oriented management makes it possible, along with economic goals, to improve the quality of services provided, adapt to the external environment, meet the interests of employees, and implement the company's development strategy.

\section{References}

1. N. Abegunasekara, Medscape Physician Business Academy - Creating a Productive and Motivated Staff, (2020)

2. C. Agomo, Understanding what motivates staff, 280, 545 (2008) 
3. Dr. Bartz, J. of human resources management and labour studies (2020)

4. M. Britnell, J. Cut the platitudes and motivate staff. Health Serv, 123, 20 (2013)

5. A. Epaneshnikov, S. Lipatova, Features of Labor Motivation Staff of the MachineBuilding Organization. Management of the Personnel and Intellectual Resources in Russia, 9, 61 (2020)

6. P. Harris, G. Howitt, N. Jones, Motivating Staff. American Journal of Nursing (1996)

7. A. Henderson, S. Schoonbeek, A. Auditore, Processes to engage and motivate staff. Nursing management, 20, 18 (2013)

8. A. Henney, Motivating staff in times of change (1996)

9. K. Lawrence, Motivating staff. Data Processing, 26, 17 (1984)

10. H. Marr, Motivating staff to higher standards. Nursing standard, 7, 31 (1992)

11. R. Oldcorn, Motivating Staff (1989)

12. R.V. Strus, O.G. Koval, O.V. Myshko, Optimize enterprise management by motivating staff. Economy and Soc ety (2018)

13. C. Thiedke, What motivates staff. Family practice management, 11, 54 (2004)

14. N. Thompson, Motivating staff, (2013) 